This is a pre-copyedited, author-produced PDF of an article accepted for publication in MODERN LANGUAGE JOURNAL following peer review. The definitive publisherauthenticated version is Modern Language Journal Volume 97, Issue 4, pages 981992, Winter 2013. doi: 10.1111/flan.12011 is available online at:

http://onlinelibrary.wiley.com/doi/10.1111/j.1540-4781.2013.12040.x/abstract

\title{
TITLE
}

\section{L2 Learners' Attitudes Toward, and Use of, Mnemonic Strategies when Learning Japanese Kanji.}

\begin{abstract}
This study investigates kanji learning (the memorization of Japanese written characters) of university students of Japanese, in order to evaluate their use of mnemonic strategies. The study applies in-depth qualitative methods to broaden the understanding of how foreign language learners use mnemonics when learning kanji. Data were collected over the duration of a year in the form of interviews, stimulated recall sessions, and a questionnaire on mnemonic usage. The study found that while mnemonics are useful to memorize kanji and kanji components when applied in a meaningful way, an over-reliance on this strategy can have negative effects for the learner. The study highlighted numerous accounts of the meaning of a kanji being lost in overly complex mnemonic strategies. Another limitation of mnemonic strategies was associations being made with the meaning of kanji and not with how it was read, causing an inability to read kanji in Japanese.
\end{abstract}

Keywords: kanji, Japanese, mnemonic, strategies, cognition, SLA

\section{INTRODUCTION}

Researchers widely agree that foreign language learners from an English-speaking background have greater difficulty learning Japanese compared to learning European languages (Bourke, 1996; Douglas, 1992; Dwyer, 1997; Everson, 2011; Sayeg, 1996; Toyoda, 1998, 2000; Toyoda \& Kubota, 2001). One study found that university students of Japanese progress more slowly in language development than students of other languages in terms of overall proficiency (Dwyer, 1997). In fact, Walton (1993) claimed that it takes English-speaking students of Japanese three times as long to acquire the same level of proficiency as European languages. More recently, Everson (2011) used a study of language training required for State Department employees (Jackson \& Malone, 2010) to suggest Japanese takes at least four times as long to acquire than European languages. Another study has linked students' difficulties in learning Japanese to a high attrition rate in Japanese language programs at Australian universities - especially in the case of learners from an English-speaking background (Kato, 2002). Dwyer (1997) also found students of Japanese were not reading as much as students of European languages, due to the challenges of the Japanese writing system. Indeed, Everson (2011) claims that the characterbased writing system "presents special challenges for learners whose first language (L1) employs the Roman alphabet" (p. 251). 
Kanji are logographic characters that originated in China and represent language through morphemes (meaning-based units) rather than phonemes (sound-based units). Due to the historical adaptation of kanji to the Japanese language, most kanji have developed multiple readings, which are defined as ways to pronounce a single character depending on its context and use, thereby adding an extra challenge for the Japanese language learner. There are more than 10,000 kanji in written Japanese, and knowledge of the 2,000 most frequently occurring enables language users to attain functional literacy in the language, because they make up more than $99 \%$ of kanji in printed documents (Cook \& Bassetti, 2005).

The difficulties of learning kanji have been well documented, especially for learners from an alphabetic language background. Much research into kanji learning, therefore, has explored methods or strategies that can assist learners to memorize kanji more effectively and efficiently. One aspect of memorization that has interested researchers is the examination of mnemonic strategies. From a cognitive perspective a mnemonic strategy is defined as "a method for enhancing memory performance by giving the material to be remembered a meaningful interpretation" (Anderson, 2005, p. 461).

Since Japanese language education began to boom in the early 1980s, the commercial textbook market has seen a number of books that promote mnemonic strategies as a way to help students learn kanji more effectively (e.g., Heisig, 2007, 2008; Henshall, 1988; Rowley, 1992; Stout \& Hakone, 2011). Rowley's book encourages the use of mnemonics with a pictorial strategy, which involves relating the kanji or kanji components to pictures of what they represent. While this strategy seems easy to apply to kanji that are symbolic representations of their meaning, matters are less straightforward with more complex or abstract kanji, as is evident from Rowley's (1992) own admission: "Several common kanji have been excluded [from the book] because frankly I couldn't come up with a satisfactory visual or textual mnemonic" (p. 8).

Heisig's (2007) book-now in its $6^{\text {th }}$ edition-lays out a more systematic approach to mnemonic use by breaking kanji into components that include what he terms "primitive elements" (p. 13), defined as the reoccurring components that are present in a number of kanji that may give clues to the kanji's meaning. In research into kanji learning, researchers favour the term grapheme (Toyoda, 2000) or component (Flaherty \& Noguchi, 1998) to describe the smallest meaningful unit that a kanji can be broken into. Although both terms are used interchangeably, this article uses the term component. It is important to note that a component may or may not be the radical (root component of a kanji for classification purposes). For example, a learner could break the kanji 語 [language] into the components 言 [speak], 口 [mouth] and 五 [five], of which only 言 [speak] is the radical. In Heisig's (2007) book the kanji are presented with stories connecting these components to hint at the kanji's meaning, although little reference to the kanji's reading in Japanese is made. That is, while a mnemonic strategy may be used to connect the kanji 下 [below] to its meaning, the same mnemonic strategy provides no indication whether the kanji should be read ge, shita, kuda, ka or sa, all of which are possible. Other authors, such as Stout and Hakone (2011), go to great length to apply complicated mnemonic strategies to even simple kanji. As an example, the authors teach the kanji for the number 9, as a pictographic representation of "a hand reaching something - nine is the number before reaching ten" (Stout \& Hakone 2011, p. 18). Here, the learners are encouraged to use a mnemonic strategy in conjunction with a pictorial strategy (associating kanji with images). At the more intermediate or advanced level of kanji learning, the learner is often encouraged to use a mnemonic strategy with a component analysis strategy. A simple illustration of this strategy using the previous mentioned kanji for language [語] is the mnemonic 'My 
mouth can speak five languages': it associates the kanji components of speak [言], five [五] and mouth [D] with the meaning of language. Heisig (2007) argues that students might be embarrassed to apply a mnemonic strategy due to its "academic silliness" (p. 3), but an organised approach to using mnemonic strategies can help students attain the goal of "native proficiency in writing the Japanese characters" (p. 7).

Despite these authors' assertion of the benefits of mnemonics in kanji learning, none of the cited books provide empirical evidence that their techniques work, nor do they make reference to academic studies that have explored mnemonic strategy use in the learning of kanji. In one such study, Lu, Webb, Krus and Fox (1999) found that learners learned kanji more effectively when the kanji were introduced with mnemonic strategies than when kanji were presented without such mnemonics. This quasi-experimental study highlights the effectiveness of using mnemonic strategies, but the results are not easily generalizable to real learning environments where students often employ multiple strategies at the same time. In two Australian studies of university students, Toyoda (1998) and Burke (1996) both found mnemonics to be useful to students. Indeed, the learners in Toyoda's (1998) study ranked mnemonics as the second most used of four strategies. However, that finding must be interpreted with some caution inasmuch as the highest ranked of the four strategies was the analysis of a kanji's components which is a strategy often used alongside, and not in opposition to, mnemonic strategies. Nevertheless, these 3 studies illustrate the benefits to memorization that mnemonic strategies have for the kanji learner.

Less encouraging of the benefits of mnemonics are two studies that detected little significant impact on a student's ability to memorise logographic scripts. Sakai's (2004) study examined the learning of kanji through mnemonics, compared to learning through context and rote memorisation; and Wang and Thomas' (1992) study compared mnemonic strategies to rote learning. Once more results must be interpreted with caution, because these two strategies are not mutually exclusive and can be employed at the same time. Specifically, from a cognitive perspective, mnemonic strategies are used to enhance encoding of new information, and rote learning retrieves this encoded information. These approaches, therefore, are looking at two very different parts of the cognitive process. Because previous research has yielded mixed results, not least for methodological reasons, it is worth investigating mnemonic strategies from a somewhat different vantage point in order to come to understand them more fully.

\section{METHODOLOGY}

\section{Research Method}

The research being reported here used a mixed-method qualitative approach in a case study context. In that decision it responds to both critics and defendants of language learning strategy research who emphasize the importance of qualitative research that goes beyond the frequent reliance on questionnaires. Thus, according to Tseng, Dörnyei and Schmitt (2006), "researchers need to apply other, more qualitative methodologies (such as stimulated recall and structured observation) to achieve a fuller understanding of the whole picture" (p. 98). Strategy use is not only a highly individualized action, it is also environment- and context-specific (Macaro \& Grenfell, 2007; Rose, 2012b; Rubin, Chamot, Harris \& Anderson, 2007; Woodrow 2005) and therefore requires a highly individualized approach. This justifies the methodological choice of a case study approach, which facilitated the kind of in-depth and contextualized exploration of mnemonic strategy use that has largely eluded previous methodological approaches. 


\section{Instrumentation}

For data collection the study used semi-structured interviews, stimulated kanji recall tasks and a simple questionnaire; the questionnaire was not subjected to statistical analysis but was used to triangulate data and as stimulus for discussion in initial interview (see the subsequent discussion). The study itself is part of a larger research project (see Rose, 2010) that investigated a range of aspects connected to kanji learning including cognitive processes, the self-regulation of kanji learning, motivation, and affect (see Rose, 2012a; Rose, 2012b for articles on theoretical findings, and Rose \& Harbon, 2013 for results of the self-regulation aspect of the larger project). By contrast, the current article focuses on evidence regarding mnemonic strategy use obtained from the three previously mentioned instruments.

Ten interviews were held over the course of an academic year; these coincided with 10 kanji tests for the participants over that time period. Participants were asked to elaborate on their approaches to learning kanji in advance of each kanji test (see Appendix A for a full list of interview questions and follow-up prompts). Comments relating to mnemonic usage were coded using NVivo data analysis software.

The inclusion of a stimulated recall task reflects recent recommendations such as those by Tseng et al. (2006), who observed "We must note at this point that increased utilization of stimulated recall methodology (cf. Gass and Mackey, 2000) offers a promising future research direction in this area, but so far little research has been done in this vein" (p. 82). Mackey and Gass (2005) define stimulated recall as "an introspective technique for gathering data that can yield insights into a learner's thought processes during language learning experiences. Learners are asked to introspect while viewing or hearing stimulus to prompt their recollections" (p. 226). For this study, the stimuli used in the recall task were the kanji tests based on kanji lists the students had studied in the preceding weeks. These tests required the students to write the meaning in English and reading in Japanese of each kanji, which appeared in the context of a sentence. Participants were asked to describe the process by which they could recall each kanji that appeared on the test. In other words, the specific process involved retrieval, which Matlin (2005) defines as locating and accessing information in memory: students access each kanji via the associations used to encode the kanji when learning, thus giving clues on how the kanji has been memorized. Because written production was not required on the tests, it was excluded from the study and its design considerations.

Similarly differentiated methodological considerations informed inclusion of a questionnaire, on which students reported their strategy use. Items on the questionnaire were adapted from Bourke's (1996) Strategic Inventory of Learning Kanji in a fashion that required the provision of answers on a linear scale, as opposed to being frequency-based. That decision reflected recent fundamental critiques of strategy inventories such as Oxford's (1990) SILL by researchers like Dörnyei (2005) and Woodrow (2005). As already mentioned, no statistical analysis was conducted on the questionnaire data thereby avoiding psychometrically compromised approaches to research (Dörnyei, 2005). Instead, participant responses on the questionnaire provided useful stimuli during the initial interview to elicit in-depth answers from participants regarding their strategy use.

\section{Setting}

The study was conducted in a university in the greater Tokyo area over the course of an academic year. That setting provided two beneficial qualities for case studies research. First, the 
university received a large number of foreign students on year-long exchanges, thus allowing the study to select from a large pool of students who were studying Japanese in a similar context; and, second, the program offered kanji courses separate from the remaining Japanese language curriculum, thus isolating the kanji learning task from other language skills.

The study excluded students from a language background that used a logographic script, such as Chinese, and participants needed to have a high command of English in order to take part in the interviews, which were conducted only in English.

Participants had four 90-minute lessons per week of Japanese language instruction, but kanji learning was assigned as an autonomous learning task. That programmatic decision was motivated by the fact that proficiency in Japanese is not related to kanji knowledge. In other words, it is possible to be a highly proficient speaker of Japanese who is completely illiterate and vice versa. By making kanji learning autonomous, the program allowed students to study at a level that was appropriate for them and to build up their knowledge from that point forward. From a research perspective, such an arrangement decreased the influence of teachers' instruction on the learning strategies the students employed.

As part of the kanji program, students were given lists of kanji to coincide with each of the 10 kanji tests offered in the academic year. Although these tests were conducted at the same time for all students, the kanji that appeared on the test was dependent on the level of the kanji list that the students were studying.

As a researcher I was not involved in the planning of the Japanese classes, had no part in constructing the kanji lists or tests, and had no relationship with the participants beforehand.

\section{Participants}

As previous studies have suggested a relationship between language proficiency and strategy use (Bourke, 1996; Oxford, 2001), and because research into kanji learning has suggested that it is in the beginning stages of kanji learning that students encounter most difficulty (Bourke, 1996; Sayeg, 1996), the study included complete beginners as well as more advanced learners.

A second consideration for choosing participants was the level of their perceived mnemonic strategy use during the initial interview. At the outset of the study I conducted a stimulated recall task and initial interview with 23 potential participants. Information gathered through that activity enabled me to select 12 on the basis of the likelihood that they would contribute a broad range of attitudes toward mnemonic strategy use. That decision reflects the observation by Grenfell and Macaro (2007) that "it is theoretically possible to be a 'good' beginner language learner and a 'poor' advanced learner" (p. 15). Because I was interested in a broad range of approaches I purposely included what might be seen as 'extreme' or 'deviant' cases. By that I mean students who would show extraordinarily high levels of usage of mnemonic strategies or, in reverse, students who appeared to avoid mnemonic strategies in kanji study altogether. By settling on twelve participants the study's precision, validity, and stability of findings could be strengthened inasmuch as it would permit examination of similar cases (Yin, 2002). At the same time, it would avoid too "unwieldy a number of participants for a single researcher to be able to treat the study with high complexity" (Miles \& Huberman, 1994, p. 30). Table 1 presents the twelve cases, with pseudonyms replacing actual participant names. [INSERT TABLE 1 AROUND HERE]

\section{RESULTS}




\section{Mnemonic Usage in the Stimulated Recall Session}

Stimulated recall data revealed that mnemonic strategy use among participants varied from extreme frequency (Jacob and Simon) to conscious refusal to use them (Adrian), with the remaining cases falling between these two extremes. The frequency of mnemonic strategy usage in the stimulated recall sessions is shown in Table 2, with the caveat that "qualitative analysis is not about mere counting or providing numeric summaries" (Rubin \& Rubin, 2005, p. 202).

Because the students in each test were studying different lists of kanji, statistical comparisons on these frequencies were not made. However, these frequencies provided insights and highlighted various patterns and tendencies of students' use of mnemonic strategies.

[INSERT TABLE 2 AROUND HERE]

The qualitative data from the stimulated recall sessions gave a richer understanding of how mnemonic strategies were used by students. In particular, mnemonics were in conjunction with other strategies such as pictorial association or, more commonly, component analysis. An example from a stimulated recall session of a mnemonic strategy used with a pictorial association follows:

EXAMPLE 1

The verb taberu [eat]. Yeah. It looks like a house. So, for me, I eat in a house, or I eat in a restaurant, which is like a building. So I would always think of it as the building. (Lisa, T4)

Here, Lisa associates the kanji 食 [eat] as looking like a building using pictorial association. She then relates the meaning through a mnemonic of 'eating in a restaurant', which is a type of building.

Although pictorial associations were frequent, mnemonic strategies were often used with a component analysis strategy. That is, the mnemonic strategy was connected with the components of the kanji, as illustrated in examples 2 and 3:

\section{EXAMPLE 2}

Like I always remember this one as yasumu [rest because there's a person resting under a tree. And it's not really a story, but kind of - I know this is person, and I know this is tree. And I just try to picture the person under the tree, and know that that's relaxing. ... Or like suki [to like]. I know that that's a mother and a child, and I say, what can be more pleasing than a mother with her child? Like things like that. I don't - I don't make up stories so much as I try to read the pictograph. (Craig, T3)

\section{EXAMPLE 3}

That's profit, so cutting down the stalk of rice for profit. (Simon, T6) In this example, Craig connects the kanji for yasumu [休] to its meaning of rest by making a story of its components of tree [木] and person [人] by thinking of a person resting under a tree [ 人十木 $=$ 休]. He gives another example of the kanji for like, having the components of a mother [女] and child [子], meaning like [好]. Having studied the etymology (origin of the written form) of the kanji components, Simon uses a mnemonic to associate the etymologically- based component of rice to recall the meaning of profit, in the act of harvesting rice for profit in the second example. The stimulated recall data was rich with examples of mnemonic strategies reminiscent of similar examples described in previous studies (Bourke,1996; Lu et al., 1999; Rose, 2003). 
Beyond revealing such strategy use, the stimulated recall data showed that mnemonic strategy usage occurred at all levels of proficiency. For example, beginner learner Simon and advanced learner Jacob both showed high use of mnemonic strategies (see Table 2). Similarly, infrequent users of mnemonic strategies (e.g., Adrian, Catherine, and Peter) came from all proficiency levels (High, Low and Medium, respectively).

In light of these potentially unexpected findings, the interview data add important insights to the study.

\section{Resistance to Viewing Mnemonics as 'Stories'}

In the interviews, some participants made the distinction between meaningful mnemonics (relating the meaning to actual components that have meaning) and "stories" that are less meaningful. In fact, the stimulated recall data had very few instances where participants employed a mnemonic strategy that was not also based on an association of meaningful kanji components. With the exception of Jacob (who will be discussed at some depth later), participants developed a consensus that mnemonics were useful only when meaningful; otherwise they presented obstacles to language learning.

Many of the participants were keenly aware of the use of mnemonics as a strategy in kanji learning even as they expressed strong opinions regarding the limitations to studying kanji in this way. Lisa, for example, understood the worth of mnemonics but recognized the difficulty of making meaningful connections, and their limitations for writing:

EXAMPLE 4

Yeah. That's [using mnemonics is] the only way to make it more interesting, and for it to make sense. Although what I find difficult is making up stories. And it's useful for reading kanji, but when you're trying to write it down, it's a bit hard to recall the story. So - hmm. (Lisa, T2)

On a slightly different note, Simon, who used mnemonics regularly with his autonomous study of kanji etymology, did not want to label his learning as using "stories" because of the stigma that using stories is "confabulated":

EXAMPLE 5

Interviewer: Okay. Ah, so this is what you've said with the stories.

Simon: $\quad$ Stories I don't do. It's - that's just not a tactic I have tried or thought of trying. It's not one I think would be very helpful for me, either.

Interviewer: Right. Right. There is - in a way, the etymology stories are kinds of stories. Right?

Simon: $\quad$ Yes. But I'd classify that differently. You know, I was thinking more along the lines of confabulation or something like that.

Interviewer: Okay.

Simon: $\quad$ Stories is like here's a kanji, and here's the picture that it's showing, and here's what's going on in that picture, even though that may or may not have anything to do with the etymology of the kanji.

Interviewer: Mm-hmm. Okay.

Simon: Whereas, you know, I'm - I'm trying to remember facts about the kanji as opposed to invent a story and then remember that. (Simon, T6)

It is then not surprising that in his self-report questionnaire (see Appendix B), Simon had given his own mnemonic strategy usage the lowest rating on the scale. In reality, however, Simon's use 
of stories based on etymology, such as "cutting the rice to make a profit" were a mnemonic strategy, which he used frequently (Table 2).

While Simon considered mnemonics to be "confabulated", Peter characterized mnemonics as potentially "ridiculous", even as he acknowledged their usefulness for some learners in the memorization of kanji. This is illustrated with the following example: EXAMPLE 6

At first it sounds ridiculous, if someone explains it to you: "The bunny comes out of the hole, goes around. The cat chases it through the grass to the rice field". But it still makes sense. I can remember neko [猫—cat] because of that [story]. (Peter, T1)

Nevertheless, despite stating the advantages of mnemonics, Peter displayed very few uses of mnemonic strategies in the 10 stimulated recall sessions (Table 2).

Yet more distanced toward the use of mnemonics was Adrian who expressed a complete dislike of them:

EXAMPLE 7

I don't really try to use mnemonic devices or anything. Yeah. I've just never really tried. It just seems like you're sort of going out of your way. I don't know. It just for me it's not really natural. It just seems kind of time consuming. Because a lot of times the meaning doesn't really fit in with -- I don't know. It just kind of depends. I've just kind of gone to just trying to remember it. I don't think I'm creative enough to make stories for all of these. (Adrian, T1)

This view was corroborated in questionnaire data, where Adrian rated his use of mnemonic strategies at the lowest rating on the scale (Appendix B). However, unlike the case of Simon who actually used them frequently, not one count of a mnemonic strategy was found in any of the stimulated recall sessions with Adrian (Table 2). This separated Adrian from other participants because all other participants recorded multiple uses, despite voiced resistance in interviews.

\section{The Danger of Over-reliance on Mnemonics}

At the other end of the spectrum of mnemonics use is Jacob who wholeheartedly embraced mnemonics. In stimulated recall sessions, Jacob relied on mnemonic strategies for almost all kanji recalled (see Table 2), a reflection of deliberate employment of mnemonic strategies that he had learned in a book about kanji learning, called Remembering the Kanji (Heisig, 2007), which as mentioned previously teaches mnemonics for kanji components by relating them to their meaning in English and then using more mnemonic strategies to relate these components to each other in advanced or complex kanji. The results are indeed akin to the "confabulated" stories that the other participants (e.g., Lisa, Simon and Adrian) seemed to be wary of using. Jacob describes Heisig's approach in the following example:

EXAMPLE 8

So, sometimes he'll stick very closely to what you might find in the dictionary and sometimes he'll give it a meaning which it just -- its not connected but its memorable. So we've got the kanji here. And as it says, "the picture in this kanji is not a pleasant one. It shows a large and fluffy Saint Bernard dog stretched out on the table all stuffed and stewed and garnished with vegetables - its paws in the air and an apple in its mouth. At each corner of the table sits an eager but empty mouth waiting for the utensils to arrive so the feast can begin." Now, because that's such a ridiculous story, it's incredibly easy to remember. You've got these four mouths around the table, dog in the middle, with their 
utensils. So that's the kind of thing it's based on. So the more ridiculous, the better for remembering it. (Jacob, T3)

In the stimulated recall sessions, Jacob employed this strategy to try to memorize and recall all of the kanji in all of the sessions, using stories from the same book to memorize kanji or their components and link these components together. In the interviews, Jacob explained that this mnemonic strategy filled most of his kanji study time. For example, he would often copy the stories on flashcards to test himself. He would also record the stories onto a digital audio player and listen to them in bed or on the train, leading him to be able to memorize complicated and detailed stories such as the one in the excerpt above.

According to Jacob, the reason for his high reliance on mnemonic strategies was that six months earlier he had become depressed and disheartened with the kanji learning task and had viewed the task of learning 2,000 kanji before graduation to be an unachievable goal. When a friend introduced him to the Heisig learning approach, he found that mnemonics gave him a systematic way to study kanji, which motivated him to study, and made his goals seem achievable.

At the beginning of the study Jacob was very enthusiastic about learning kanji in this way. But that feeling diminished throughout the study so that toward the end Jacob was once again feeling that he could not attain his goals because he began to notice serious limitations in the approach. The biggest limitation remained that the stories focused on English meanings of kanji presented in isolation. In many cases, especially at the advanced level, these kanji rarely appeared by themselves as a reflection of their singular meaning, but in common combinations with other kanji. Thus, often when known kanji appeared in text, Jacob was able to recognize the kanji, its story and singular (and at times abstract) meaning; but this did not help him to understand the meaning of it in the context of a sentence. Moreover, these stories, which were always entirely in English, made no association with how the character was read in Japanese, resulting in an inability to read known kanji in the Japanese language, or to look them up in a phonetic dictionary. Although he had memorized the meaning of the kanji, he had not at all studied the readings of them and came to realize that he needed to go back and relearn all the kanji and make associations with their Japanese readings. This left him disheartened that the hard work he had put into remembering the kanji had not resulted in the level of progress that he had hoped for.

\section{Losing the Meaning in the Mnemonic}

Yet more problematic, Jacob could at times recall the mnemonic strategy, but not the meaning, as in the following example:

EXAMPLE 9

Some of them are quite ridiculous. "There's this monster on the ceiling that likes to eat nails and then spit them in people's heads". I remember the story, but I can't remember the kanji right now. I haven't revised these [kanji] now for about three months or longer.

I find after three months it's terrible. (Jacob, T8)

Here, Jacob recalls a "ridiculous" story, but fails to remember the kanji it is connected with.

The same phenomenon of losing the meaning in the mnemonic was evident with other learners as well, especially with frequent mnemonic strategy users. Simon would often remember the etymological origins of kanji components and then forget the meaning of the kanji they were presented in-especially if the meaning of the kanji had grown apart from its etymological origin. Catherine, who made her own mnemonic strategies, would regularly create stories 
according to pictorial associations of a kanji's components that were completely removed from the meaning, as in the following example.

EXAMPLE 10

Catherine: Yeah. Because I specifically remember that one [困] as a tree [木] in a box [口].

Interviewer: Okay. But how does that link in with the meaning of trouble? Or you just

Catherine: I don't know what the meaning is. (Catherine, T9)

Here, Catherine remembers the story, but it fails to connect with the meaning of the kanji in her mnemonic - that is, her story of a tree in a box is unassociated with the kanji for komaru [困る], meaning to be in trouble. In another case, Catherine memorizes the kanji 感 [feeling], because it "looks like a bug that's been squashed", but was unable to recall its meaning. This was a reoccurring phenomenon in Catherine's application of mnemonic strategies and differentiated her from other participants who tried to make meaningful associations with mnemonics, even when confabulated.

In sum, evidence for the phenomenon of losing the meaning in mnemonic arose a number of times in the stimulated recall sessions, especially with participants who relied heavily and consciously on mnemonic strategies. It tended to be the result of making stories that were removed from the meaning of the kanji. That is, saying a kanji looks like a monster on the ceiling spitting nails into people's heads does not necessarily evoke its real meaning, an insight to which some participants gave voice. In fact, Peter commented on this during one of the initial interviews:

Interviewer: If there's no clear connection between the compounds, you wouldn't use this technique?

Peter: $\quad$ No.

Interviewer: At all?

Peter: $\quad$ No. Because like maybe that helps in memorizing them, but if I'm trying to read something, you know, you don't have time to sit there and go, okay, the bunny came out of the hole, so that kanji must mean this. You know? (Peter, T1)

Here Peter, like Simon, emphasizes the use of mnemonics only when it makes sense, and avoids applying mnemonics in nonsensical or "confabulated" ways.

\section{DISCUSSION AND CONCLUSION}

Implications for Learners and Instructors

While mnemonic strategies were clearly useful to a number of learners in this study, data revealed limitations to the exclusive use of a mnemonic approach. Such findings have clear implications for the Japanese language learner and instructor.

Data indicated that mnemonic strategies were useful when applied in a meaningful way, but were less helpful when associations became convoluted or complex. Results indicate convoluted mnemonic strategies, which link advanced kanji to meaning and not the Japanese reading, may result in an inability for the learner to read the kanji in Japanese, or recall the meaning altogether. Results also indicate adherence to a systematic approach of mnemonic strategies can lead to feelings of defeat when knowledge of kanji does not advance as expected.

While this study warns against the shortcomings of a mnemonic approach, it does concur with previous studies that show mnemonics to be a useful strategy for students of Japanese (e.g. Lu et al., 1999, Toyoda, 1998), but qualifies this finding by arguing that it is only useful when 
meaningful associations can be made, which trigger both the meaning and the reading of the kanji. Logically, mnemonics might prove less useful for kanji that are rarely used in isolation of other kanji, or are semantically abstract, as is the case for many advanced kanji. Therefore, teachers and learners alike should be wary of commercial textbooks that claim a systematic approach to mnemonics for all kanji can help learners attain native proficiency in written Japanese. Certainly such claims cannot be supported by this study, nor the findings of previous empirical research into kanji learning strategies.

\section{Implications for Further Research}

This study has helped to build on contradictory findings of the benefits of mnemonic strategies in kanji learning, by exploring mnemonic strategy use from a different research approach than previous studies, which trended towards quasi-experimental or survey designs. By situating the examination of mnemonics in a larger study of strategy use (Rose, 2010), this article examined how learners use mnemonic strategies alongside other strategies. Future studies might also consider an approach where use of mnemonic strategies can be measured in conjunction with (and not in opposition to) strategies such as component analysis, and pictorial association.

In terms of data collection, stimulated recall data shed light on the types of mnemonic strategies employed by learners, concurring with recent recommendations for the inclusion of this instrument in strategy research (Dornyei, 2005; Rose, 2012b, Tseng et al., 2006). Qualitative interview data revealed the impetus behind choosing or avoiding mnemonic strategies, and the self-perceived impact they had on learning. By comparing data from the questionnaire and interview with the stimulated recall task, limitations to self-report instruments were also revealed in the form of learners who reported not using mnemonic strategies which were observed in stimulated recall and vice versa. This concurs with previous studies, which have warned against the reliability of self-report data in strategy research (Rose, 2012b; Tseng et al., 2006; Woodrow, 2005).

A limitation of the study is that the context involved the learning of kanji lists for reading tests, and thus the important role of reading authentic texts in the learning process (Everson, 2011), and the written production of kanji were not included in the study design, indicating possibilities for future studies. Furthermore, as the cases in this study were learning different lists of kanji, analysis of mnemonic strategy use according to kanji was not possible across cases, and thus a future study that examines a cohort of learners engaged in the same level of learning could reveal interesting results regarding a correlation between types of kanji and mnemonic strategies.

\section{Conclusion}

In conclusion, results have suggested mnemonic strategies provide both benefits and limitations in the kanji-learning task. In terms of attitudes toward this cognitive strategy, while some participants perceived mnemonics as a useful strategy for kanji learning, others perceived them as "ridiculous" stories. A further examination of the cases revealed that an overuse of mnemonic strategies caused limitations in learner recall of kanji due to the multiplicity of kanji readings. The findings not only support the use of meaningful mnemonic strategies, but also warn Japanese language learners and instructors of the dangers of relying too heavily on them. This study also exposes limitations to the sole use of mnemonic strategies, which are encouraged by a number of commercial kanji learning textbooks. The study has also highlighted implications for future kanji research, and the findings support movements toward interviews and stimulated 
recall data collection instruments when looking at kanji learning, in place of the self-report questionnaires that have traditionally been used.

\section{ACKNOWLEDGMENTS}

I would like to express my sincere gratitude to the anonymous MLJ reviewers for their insightful comments, and to Heidi Byrnes for her valuable input on this article.

\section{REFERENCES}

Anderson, J. R. (2005). Cognitive psychology and its implications. (6th ed.). New York: Worth publishers.

Rose, H. (2003). Teaching learning strategies for learner success. Babel, 32, 32-38.

Rose, H. (2010). Kanji learning of Japanese language learners on a year-long study exchange program at a Japanese university: An investigation of strategy use, motivation control and self-regulation. (Unpublished doctoral dissertation). The University of Sydney, Australia.

Rose, H. (2012a). Reconceptualizing strategic learning in the face of self-regulation: Throwing language learning strategies out with the bathwater. Applied Linguistics, 33, 92-98.

Rose, H. (2012b). Language learning strategy research: Where do we go from here? Studies in Self-Access Learning Journal, 3, 137-148.

Rose, H. \& Harbon, L. (2013). Self-regulation in second language learning: An investigation of the kanji-learning task. Foreign Language Annals, 46, 96-107.

Bourke, B. (1996). Maximising the kanji learning task. (Unpublished doctoral dissertation). The University of Queensland, Australia.

Burns, R. B. (2000). Introduction to research methods. London: Sage.

Cohen, L., Manion, L, \& Morrison, K. (2007). Research methods in education. (6th ed.). Oxon, UK: Routledge.

Cook, V., \& Bassetti, B. (2005). Second language writing systems. Clevedon, UK: Multilingual Matters.

Dörnyei, Z. (2005). The psychology of the language learner: Individual differences in second language acquisition. Mahwah, NJ: Lawrence Erlbaum.

Douglas, M. O. (1992). Development of orthography-related reading and writing strategies by learners of Japanese as a foreign language. (Unpublished doctoral dissertation). The University of Southern California, USA.

Dwyer, E. S. (1997). Getting started the right way: An investigation into the introduction of kanji study to neophyte Japanese learners. (Unpublished doctoral dissertation). The University of Texas, TX.

Everson, M. E. (2011). Best practices in teaching logographic and non-roman writing systems to L2 learners. Annual Review of Applied Linguistics, 31, 249-274.

Flaherty, M. \& Noguchi, M. S. (1998). Effectiveness of different writing approaches to kanji education with second language learners. JALT Journal, 20, 60-78. 
Heisig, J. W. (2007). Remembering the Kanji, Vol. 1: A Systematic guide to reading Japanese characters. Honolulu: University of Hawaii Press.

Heisig, J. W. (2008). Remembering the Kanji, Vol. 2: A Systematic guide to reading Japanese characters. Honolulu: University of Hawaii Press.

Henshall, K. G. (1988). A guide to remembering Japanese characters. North Clarendon, VT: Tuttle.

Jackson, F. H., \& Malone, M. E. (2010). Building the foreign language capacity we need: Toward a comprehensive strategy for a national language framework. Washington, USA: Center of Applied Linguistics. Retrieved December 10, 2012, from http://www.cal.org/resources/pubs/building-the-foreign-language-capacity-we-need.html

Kato, F. (2002). Efficacy of intervention strategies in learning success rates. Foreign Language Annals, 35, 61-72.

Lu, M., Webb, J. M., Krus, D. J., \& Fox, L. S. (1999). Using order analytic instructional hierarchies of mnemonics to facilitate learning Chinese and Japanese kanji characters. The Journal of Experimental Education, 67, 293-311.

Macaro, E. \& Grenfell, M. (2007). Claims and critiques. In D. C. Cohen \& E. M. Macaro (Eds.), Language learner strategies (pp. 9-28). Oxford: Oxford University Press.

Mackey, A. \& Gass, S. (2005). Second language research: methodology and design. Mahwah, NJ: Lawrence Erlbaum.

Matlin, M. W. (2005). Cognition. (6th ed.). Hoboken, NJ: John Wiley \& Sons.

Miles, M. B., \& Huberman, A. M. (1994). Qualitative data analysis. Thousand Oaks, CA: Sage.

Oxford, R. L. (1990). Language learning strategies: What every teacher should know. Boston, MA: Heinle \& Heinle.

Oxford, R. (2001). Language learning strategies. In D. Nunan \& R. Carter (Eds.), The Cambridge guide to teaching English to speakers of other languages (pp.166-172). Cambridge: Cambridge University Press.

Rowley, M. (1992). Kanji pict-o-graphix: over 1,000 Japanese kanji and kana mnemonics. Berkeley, CA: Stone Bridge Press.

Rubin, J., Chamot, A. U., Harris, V., \& Anderson, N. J. (2007). Intervening in the use of strategies. In D. C. Cohen \& E. M. Macaro (Eds.), Language learner strategies (pp. 141160). Oxford: Oxford University Press.

Rubin, J. H., \& Rubin, I. S. (2005). Qualitative interviewing. The art of hearing data. Thousand Oaks, CA: Sage.

Sakai, J. (2004). Imagery mnemonic versus context learning: Effects on kanji retention (Unpublished masters thesis). California State University, CA.

Sayeg, Y. (1996). The role of sound in reading kanji and kana: A review. Australian Review of Applied Linguistics, 19, 139-151.

Stout, M., \& Hakone, K. (2011). Basic Japanese kanji volume 1: High-frequency kanji at your command. North Clarendon, VT: Tuttle. 
Toyoda, E. (1998). Teaching kanji by focusing on learners' development of graphemic awareness. Australian Review of Applied Linguistics, 21, 155-168.

Toyoda, E. (2000). English speaking learners' use of component information in processing unfamiliar kanji. Australian Review of Applied Linguistics, 23, 1-14.

Toyoda, E. \& Kubota, M. (2001). Learning strategies employed for learning words written in kanji versus kana. Australian Review of Applied Linguistics, 24, 1-16.

Tseng, W. T., Dörnyei, Z., and Schmitt, N. (2006). A new approach to assessing strategic learning: The case of self-regulation in vocabulary acquisition. Applied Linguistics, 27, 78102.

Walton, A. R. (1993). Japanese language in US high schools: A new initiative. Modern Language Journal, 77, 522-523.

Wang, A. Y. \& Thomas, M. H. (1992). The effect of imagery on the long-term retention of Chinese characters, Language Learning, 42, 359-376.

Woodrow, L. (2005). The challenge of measuring language learning strategies. Foreign Language Annals, 38, 90-100.

Yin, R. K. (2002). Case study research, design and methods. Thousand Oaks, CA: Sage. 
TABLE 1:

Participants

\begin{tabular}{lll}
\hline Proficiency in kanji & Participant & Country of background \\
\hline High & Jacob+ & UK \\
& Sia & UK \\
& Harold & Australia \\
& Adrian* & USA \\
Medium & Craig+ & USA \\
& Peter & USA \\
& Jerry & USA \\
Low & Tim* & Australia \\
& Simon+ & USA \\
& Catherine & USA \\
& Lisa & UK \\
& Sarah* & USA \\
\hline
\end{tabular}

Note. Proficiency was based on number of known kanji according to a placement test administered by the university where the participants studied. This proficiency test was used to place students in appropriate level classes. Low indicates knowledge of less than 200 kanji.

Intermediate indicates knowledge of 200-800 kanji. Advanced indicates knowledge of more than 800 kanji. +Indicates a participant chosen as a potential extreme case. *Indicates a participant chosen as a potential deviant case.

\section{TABLE 2:}

Frequency of Mnemonic Strategy Use in Stimulated Recall Sessions, for each of the 10 Kanji Tests

\begin{tabular}{llllllllllll}
\hline Name & T1 & T2 & T3 & T4 & T5 & T6 & T7 & T8 & T9 & T10 & TOTAL \\
\hline JACOB & 20 & 18 & 20 & 19 & 20 & 20 & 20 & 19 & 20 & 20 & 196 \\
SIMON & 14 & 13 & 11 & 8 & 8 & 6 & 12 & 14 & 15 & 15 & 116 \\
HAROLD & 8 & 6 & 11 & 4 & 7 & 4 & 7 & 7 & 3 & 5 & 62 \\
SIA & 4 & 7 & 3 & 7 & 6 & 5 & 3 & 5 & 4 & 6 & 50 \\
LISA & 4 & 3 & 2 & 4 & 3 & 5 & 4 & 5 & 5 & 5 & 40 \\
TIM & 4 & 3 & 5 & 2 & 4 & 3 & 4 & 2 & 4 & 1 & 32 \\
SARAH & 0 & 4 & 3 & 2 & 4 & 2 & 0 & 1 & 3 & 2 & 21 \\
CRAIG & 2 & 1 & 0 & 1 & 3 & 2 & 4 & 2 & 1 & 0 & 16 \\
JERRY & 0 & 1 & 2 & 1 & 1 & 4 & 2 & 0 & 1 & 1 & 13 \\
CATHERINE & 1 & 0 & 3 & 2 & 1 & 1 & 1 & 2 & 0 & 0 & 11 \\
PETER & 2 & 1 & 0 & 2 & 0 & 0 & 0 & 1 & 2 & 3 & 11 \\
ADRIAN & 0 & 0 & 0 & 0 & 0 & 0 & 0 & 0 & 0 & 0 & 0 \\
\hline
\end{tabular}





\section{APPENDICES}

Appendix A: Interview Questions

The interview questions have been organized into main questions, which were always asked to all participants, and probes used to elicit more information where necessary.

Part One (For Initial Interview only):

These questions concern students' past experiences of studying Japanese.

i. Can I first ask you about your Japanese learning background? Probes: How long have you studied Japanese? / Where have you studied?

ii. What kinds of learning have you taken part in? Probes: What kind of Japanese classes have you taken in the past? / How active where these classes? / What did a typical lesson consist of?

iii. How do feel about learning kanji in your Japanese learning so far? Probes: Do you find it difficult? Fun? Challenging? Over-whelming / How much do you already know? / How do you feel about studying kanji in the future?

Part Two (for Initial and Ongoing Interviews):

These questions concerned students' kanji learning in the preceding week(s).

i. Remember back to your last Japanese kanji/writing class. What did you do? Probes: How did you study them or learn them? / How were they introduced by the teacher? / Did the teacher show you ways to remember any of the kanji more easily? If yes, what?

ii. How have you been studying kanji? Probes: How have you studied them? / How long did you spend in each study session? / Probe for reflections on strategy use, study habits, difficulties of learning and external factors that may have affected study, i.e. reasons for under or over performance.

iii. Reflecting on your kanji learning in the past week(s), how do you think you have performed?

iv. Can I finally ask you if there is any aspect of your experience of learning kanji that has not been covered in this interview?

\section{Part Three (Stimulated Recall):}

This task examined the cognitive processes of how students remembered and recalled kanji learned in the preceding week(s).

i. I am going to show you a list of kanji, which you have been studying. I want you to tell me the reading or meaning of the kanji and any information on how you remember it. Probes: How did you remember it? / How do you know that is the answer? / Did you remember it in any special way? 

Appendix B: Questionnaire Results

\begin{tabular}{llll}
\hline & Q1 & Q2 & Q3 \\
\hline Adrian & 1 & 1 & 1 \\
Craig & 5 & 5 & 3 \\
Harold & 2 & 5 & 1 \\
Jerry & 7 & 2 & 1 \\
Jacob & 3 & 7 & 7 \\
Catherine & 4 & 2 & 4 \\
Lisa & 4 & 4 & 4 \\
Peter & 1 & 1 & 1 \\
Simon & 1 & 1 & 1 \\
Sia & 6 & 6 & 2 \\
Tim & 3 & 5 & 6 \\
Sarah & 6 & 3 & 2 \\
\hline
\end{tabular}

Note. Q1 I make up my own stories according to what the kanji looks like to me; Q2 I make up my own stories according to the component elements of the kanji; Q3 I use stories told to me by my teacher or in reference books; Scale $1=$ not true of me at all; $7=$ very true of me 